\title{
De saberes, pasiones y repugnancias Reflexiones en torno a algunas tensiones culturales en la implementación de la educación sexual integral en escuelas católicas en la ciudad de La Plata
}

(1) Guillermo Romero*

Recibido

octubre de 2017

Aceptado

marzo de 2018

\begin{abstract}
Resumen
El artículo describe y analiza algunas tensiones relevadas en torno a la implementación de la educación sexual en escuelas católicas en la ciudad de La Plata en el marco de la obligatoriedad de instrumentar una política educativa con perspectiva de género como la Educación Sexual Integral (ESI) a la que la Iglesia Católica y en particular el arzobispado platense se oponen abiertamente. En este caso, el trabajo explora acerca de los "límites culturales" que dificultan la plena implementación de esta política, con énfasis en la estructura de sentimientos subjetivos que sostienen las prácticas de docentes y directivos.
\end{abstract}

\section{On knowledge, passions and disgust. Reflections on cultural ten- sion in the implementation of Comprehensive Sexual Education in Catholic schools in the city of La Plata}

\section{Palabras clave}

Educación sexual; Educación religiosa; Límites culturales; Pánico sexual; Género

\begin{abstract}
The article describes and analyzes some of the tension involved in the implementation of sexual education in Catholic schools in the city of La Plata, within the framework of the obligation to implement an educational policy with a gender perspective, such as the National Program of Comprehensive Sexual Education (ESI, according to its Spanish initials), which the Catholic Church and in particular the La Plata Archbishopric openly oppose. In this case, the paper explores the "cultural limits" that hinder the full implementation of this policy, with emphasis on the structure of subjective feelings that underlie the practices of teachers and school principals.
\end{abstract}

Key words

Sex education; Religious education; Cultural limits; Sexual panic; Gender 
Palavras-chave

Educação sexual; Educação religiosa; Limites culturais; Pânico sexual; Gênero

\section{De conhecimentos, paixões e repugnâncias. Reflexões sobre algumas tensões culturais na implementação da Educação Sexual Integral em escolas católicas na cidade de La Plata}

\section{Resumo}

O artigo descreve e analisa algumas das tensões relacionadas à implementação da educação sexual em escolas católicas na cidade de La Plata, Província de Buenos Aires, na Argentina, no âmbito da obrigação de implementar uma política de educação de gênero como a Educação Sexual Integral (ESI) a que a Igreja Católica e, em particular, o arcebispado de La Plata, se opõem abertamente. Neste caso, o trabalho explora os "limites culturais" que impedem a plena implementação desta política, com ênfase na estrutura de sentimentos subjetivos que apoiam as práticas de professores e os diretores das escolas.

Es una mañana soleada y me acerco caminando distraído a la escuela. Hace más de un año y medio que visito colegios secundarios católicos situados en la ciudad de La Plata con el fin de analizar diferentes experiencias de educación sexual y hace ya varios meses que voy todas las semanas a esta escuela en particular. ${ }^{1}$ Media cuadra antes de llegar, comienzo a observar al grupo de estudiantes (varones y mujeres) que están reunidos afuera del edificio, frente a la puerta de entrada, en torno a una fuente vacía que utilizan habitualmente como espacio de encuentro. Por alguna razón que en ese momento no logro entender, la escena llama mi atención de inmediato. Me concentro en los intercambios verbales (me llegan algunas risas y los comentarios más altisonantes), pero sobre todo en la disposición de los cuerpos (las posturas, las distancias y los contactos).

Al llegar al lugar toco el timbre con el fin de ingresar a la escuela y quedo de espaldas al grupo, aunque todavía atento a lo que allí sucede. En ese momento, dos chicas se desprenden del resto y enfilan hacia el edificio con el fin de aprovechar la apertura de la puerta y entrar ellas también. Se acercan riéndose, por momentos abrazadas, y esperan detrás de mí. Es evidente el esfuerzo que hacen por componerse, pero sucede que esa contención les juega en contra y, luego de un esforzado silencio, sobrevienen risas nerviosas, contenidas a medias, que vuelven a ahogarse de manera abrupta, para dar paso una vez más a una risa estruendosa que se termina de apagar al abrirse la puerta y emerger del otro lado el rostro adusto del preceptor, quien indudablemente las había escuchado.

Antes de saludarlo, me hago a un lado para dejar ingresar a las estudiantes y poder conversar con él a solas y noto cómo las jóvenes pasan con el cuerpo erguido, ya sin tocarse, procurando no hacer el más mínimo ruido, y atraviesan así el primer patio, para desarmar por fin esa postura al ir llegando al segundo patio, supuestamente fuera del alcance de las autoridades del colegio, donde nuevamente se desata un ataque de risa que vuelve a poner de mal humor al preceptor.

$\mathrm{Al}$ reconstruir horas más tarde lo observado (y lo sentido) en esta visita, me quedé un buen rato repasando esta escena. ¿Cómo interpretar lo sucedido? ¿Qué había llamado tanto mi atención de esta escena cotidiana? ¿Qué podía señalar esta pequeña situación escolar respecto de mis propósitos de comprender las experiencias de educación sexual en esta y otras escuelas católicas? 
En primer lugar, aunque en el momento no había sido capaz de ponerlo en discurso, luego se me hizo evidente que las/os ${ }^{2}$ jóvenes reunidas/os en la fuente habían captado mi atención de inmediato por cuanto sus intercambios contrastaban ostensiblemente con lo que había observado en el interior del colegio. Al verlo de ese modo, noté que incluso en mi caso, aunque nadie me lo hubiera señalado, desde el primer momento había adquirido algún tipo de comprensión que hizo que supiera adecuar mi aspecto y mi disposición corporal a una suerte de economía emocional-libidinal extremadamente ascética que regía los intercambios al interior de esta institución, algo que había experimentado (y así dejé registro de ello en mis notas de campo) como un cansancio corporal desmedido, como si comportarme acorde con lo esperado me insumiera una cantidad de energía a la que no estaba acostumbrado.

Si bien la regulación del cuerpo constituía un punto de partida de mi indagación, algo contemplado ya en el primer borrador de una grilla de relevamiento que elaboré para tal fin, lo cierto es que fue recién en este momento (¡después de un año y medio!) que comprendí que cada escuela instituía una economía de los cuerpos y las emociones específica. Si bien dicha configuración regulatoria era permanentemente negociada y puesta en tensión de múltiples maneras - como en el caso de las/os jóvenes que salían del edificio y establecían allí otras lógicas de interacción-, al mismo tiempo era fácilmente captada por los sujetos sin necesidad de que estuviera escrita y fuera señalada de manera explícita cada vez (aunque múltiples y cotidianas operaciones de control tuvieran que actualizar su vigencia, como puede verse en la expresión de disgusto del preceptor).

A medida que avanzaba en la indagación, fui comprobando que la regulación corporal constituye un eje crucial para pensar las prácticas de educación sexual en los colegios, no sólo (como creía inicialmente) en tanto normalización de los cuerpos en función de una configuración cultural dada - esto es, en tanto adecuación a los parámetros hegemónicos de normalidad y belleza-, sino también en tanto constricción de las energías, las emociones, las efusividades y los deseos en el marco de la correcta convivencia escolar.

Al mismo tiempo, la centralidad de la dimensión corporal para analizar la educación sexual en las escuelas exhibe una paradoja: mientras por un lado se observa una atención casi obsesiva por los cuerpos y las formas adecuadas de conducirlos, en diversas circunstancias se hace de cuenta que estos no existen y, por lo tanto, no son contemplados en el currículum prescripto ni en las estrategias didácticas de la mayor parte de las/os docentes, quienes parecerían estar dispuestas/os a albergar sujetos exclusivamente racionales, sin tener que vérselas con los cuerpos en los que esas subjetividades se encarnan.

De ese modo, noté que en aquellas asignaturas cuyos programas prescriben obligatoriamente su estudio, el cuerpo humano aparece (solamente) como contenido curricular y reducido a su faz biomecánica y a su dimensión reproductiva y de vector de contagios, por lo general con una abundancia de lenguaje técnico que desconecta los procesos educativos de las experiencias concretas de los sujetos implicados en ellos.

Como señala Marina Tomasini, muchas veces el ámbito escolar pretende una (imposible) escisión “entre el 'ser joven' y el 'ser alumno"' (Tomasini, 2011: 121). Esa disociación empobrece la experiencia educativa, que tiende así a quedar reducida a la memorización de "órganos y funciones" que permiten aprobar una materia pero no brindan un marco de comprensión para las dudas, inquietudes y deseos en torno a las prácticas sexuales en general, ni a las coitales en particular. Si entendemos que la sexualidad "es una dimensión de la experiencia humana que implica el placer, las sensaciones, la corporalidad y el deseo (...), no podría esperarse que quede en la puerta de la escuela" (Tomasini, 2011: 121). De ese modo, la interpelación pedagógica pierde potencia entre
2. Opto por una desinencia (a/o) que incluya (y distinga) a los géneros gramaticales masculino $y$ femenino cuando hago referencia tanto a hombres como mujeres, decisión que podría ser acusada fácilmente de ratificar el binarismo sexual, excluyendo otras identidades (y formas de expresarlas) que exceden el par - pretendidamente natural-masculino/femenino. De todos modos, esta forma gramatical me permite explicitar una marcación sexo-genérica diferencial para mis informantes varones y mis informantes mujeres, especialmente relevante en algunos pasajes del trabajo. 
3. Utilizo esta palabra con la forma gramatical masculina por cuanto la dirección de las tres escuelas relevadas estaba a cargo de varones.

4. Empleo nombres de fantasía con el fin de resguardar el anonimato de mis informantes y preservarlas/os de posibles inconvenientes laborales. las/os jóvenes y deviene referencia advertida pero, toda vez que sea posible, resistida y/o subvertida en el ámbito escolar y desdeñada por fuera de él. Lo que se produce es una actuación dificultosa de la norma incapaz de contener la risa estruendosa que pugna por salir ante la imposibilidad de asimilar la pretendida ascesis corporal, que no encuentra correspondencia con el resto de la experiencia vital juvenil.

De todas formas, es preciso aclarar en este punto que no todas las escuelas católicas analizadas imponían la misma rigidez corporal y libidinal, aunque en los tres contextos educativos analizados observé, con diferentes énfasis, una importante disociación entre las prácticas de educación sexual y las experiencias concretas de los sujetos, enfoque pedagógico que asocio, más que a la adscripción ideológica al paradigma biomédico, al temor o la ansiedad que provoca en las/os adultas/os el abordaje de una temática que suponen puede ocasionar ciertos desbordes emocionales en las/os jóvenes o bien ponerlas/os a ellas/os mismas/os en situación de tener que dar cuenta de aspectos que consideran íntimos y que invocan pudor y vergüenza, sentimientos característicos del "dispositivo de sexualidad" moderno (Foucault, 2011) que operan, para algunos sujetos, como principios de clasificación relativamente incuestionados.

En esos temores e inseguridades se anudan trayectorias biográficas y formativas de las/os propias/os docentes y directivos, ${ }^{3}$ sus supuestos respecto de las/os estudiantes así como sus idearios valorativos en materia de géneros y sexualidades, constituyendo muchas veces esas tramas simbólicas las principales barreras culturales que dificultan el abordaje de una educación sexual con perspectiva de género, aspectos no siempre tenidos en cuenta ni en el despliegue de las políticas públicas ni en su estudio y que constituirán el principal objeto de análisis del presente trabajo.

\section{¿Todas/os de acuerdo? Desconocimientos, malentendidos y sabe- res diferenciales en torno a la ESI}

Cuando no estaba lo de la ley, si se podía esquivar el tema, muchas veces era mejor. Ahora es como que no podemos hacernos los sotas porque el tema se tiene que dar. Yo estoy totalmente a favor (Lorena, ${ }^{4}$ profesora de Biología).

Acaso un punto de partida (no del todo autoasumido) de mi indagación radicaba en la certeza de que en las escuelas católicas iba a encontrar una enorme resistencia por parte de algunos actores, sobre todo de directivos, frente a la exigencia estatal de aplicación de prácticas de educación sexual desde una perspectiva de género y de derechos. De ahí la profunda sorpresa que me generó encontrar desde un primer momento expresiones de pleno acuerdo con esta política educativa. "Yo estoy totalmente a favor", "la verdad es que me parece bárbaro", "me parece supernecesario", "ahora tenemos otro respaldo", fueron algunos de los comentarios que fui relevando y que evidenciaron parte de mis presupuestos no declarados. De esta forma, los resquemores iniciales fueron trocando en una mirada más entusiasta, habida cuenta de mis propios pareceres (favorables) respecto de la ESI.

Sin embargo, rápidamente advertí que esa manifestación de acuerdo y conformidad con esta política frente a un investigador externo - presumiblemente progresista en materia de posicionamientos sexo-genéricos (o, al menos, con el interés necesario como para realizar una investigación sobre estos temas) - no implicaba en absoluto ni conocimiento ni aceptación de los fundamentos conceptuales de la ley 26.150. Más bien parecía tratarse (así lo entendería después) de un intento de despegarse de las posturas del arzobispo platense, Héctor Aguer, un férreo opositor a la ESI cuyos posicionamientos (extremadamente conservadores) suelen tener gran repercusión pública y mediática. Además, al tratarse de una política que las escuelas están obligadas 
a instrumentar en la medida en que la ley la erigió en un derecho de "los educandos", resultaba esperable que, al menos inicialmente, docentes y directivos se manifestaran de acuerdo con ella y afirmaran estar implementándola.

A poco de comenzar mi indagación, fui advirtiendo la emergencia de múltiples disensos con la ESI, así como ciertos desconocimientos y malentendidos respecto de sus contenidos y sus alcances. Por otra parte, noté que la distinción con la postura arzobispal, que supuestamente dejaba a mis informantes a favor de esta política, en ocasiones generaba un efecto de consenso aparente que dificultaba la mera posibilidad de que pudiera emerger una discusión profunda respecto de la orientación de la educación sexual a implementar. En ese sentido, bucear alrededor de estos equívocos se volvió crucial para comprender las tramas significativas que iban gestando unos modos de concebir y vivir los cuerpos, los deseos, las sexualidades y los géneros en estas escuelas.

Los directivos de los tres colegios en los que realicé el relevamiento aseguraban que nunca les habían llegado los materiales elaborados por el Programa Nacional de ESI ni los producidos por el Ministerio de Educación de la Provincia de Buenos Aires. ${ }^{5}$ En cambio, directivos y docentes conocían materiales y documentos de la Iglesia católica con sus posicionamientos respecto de la moral sexual acordes con su ideario así como al modo de difundirla en el ámbito escolar.

Tal vez ello explique en parte el enorme desconocimiento en estos colegios de los postulados específicos de la ESI. De todas formas, sin negar su importancia, no se trataba solamente de un problema de "falta de capacitación", como las/os propias/os docentes se encargaban de señalar una y otra vez como obstáculo para la implementación plena de esta política, sino también - y fundamentalmente- de los saberes diferenciales puestos en juego.

Como dije previamente, luego de un gesto inicial de concordancia con la ESI por parte de los actores con los que entré en contacto en estas escuelas, de a poco fueron manifestándose diferentes signos de disidencia con algunos de sus fundamentos o propósitos formativos. Con la particularidad de que algunas veces esos desacuerdos se planteaban respecto de sus alcances supuestos por las/os docentes y directivos, los que en ocasiones no se condecían con los lineamientos de esta política plasmados en los documentos y materiales específicos.

Una zona en la que estos malentendidos aparecían recurrentemente en las tres escuelas era la vinculada a las materias y los niveles en que debía abordarse la educación sexual, desconociendo uno de sus principios básicos, que es la voluntad de plantear ejes transversales a la propuesta curricular integral desde el nivel Inicial. En este sentido, una profesora me señaló en una ocasión que, a su entender, uno los principales problemas de la ESI era que se circunscribía a "Salud y Adolescencia, que está en Cuarto, que para mi gusto ya es muy avanzado (...) porque hoy en día ya en Séptimo tenemos chicos que inician la actividad sexual, nenas sobre todo, y sin información" (Patricia, docente de Biología de escuela congregacional). Por su parte, una profesora de Salud y Adolescencia, que coincidía con el supuesto de que la ESI se reducía a su materia, también reclamaba "que esta materia se dé en un año anterior" (Docente de Salud y adolescencia de escuela congregacional). Luego de reiteradas entrevistas, y habiendo transcurrido un tramo importante de mi trabajo de campo, comprendí que las distintas docentes de Salud y Adolescencia entrevistadas tendían a confundir la ESI con la ley de salud sexual y procreación responsable (25.673), en la que se basan los contenidos de dicha asignatura. Ello podría explicar, en parte, que estas profesoras priorizaran un enfoque preventivo en su abordaje de la educación sexual, aunque el currículum oficial de la materia (no así los manuales de editoriales privadas que muchas veces se utilizan en su reemplazo) desborda y hasta discute abiertamente dicha perspectiva.
5. En la medida en que el sistema educativo argentino es federal, cada provincia instrumentó una modalidad particular para la implementación de esta política. De acuerdo con el testimonio de un informante clave que participó en los diálogos con actores ministeriales de distintas jurisdicciones del país, los perfiles y los compromisos fueron heterogéneos y cambiantes. Hubo provincias que fortalecieron la ESI con iniciativas, leyes y materiales propios orientados por la misma perspectiva, a la vez que en otras jurisdicciones hubo actores que dificultaron todo lo posible su implementación (por ejemplo, evitando la realización de capacitaciones y/o reteniendo los materiales enviados desde el Ministerio de Educación de la Nación). En ese marco, al momento de nuestra indagación (2011-2012), el mismo informante consideraba que la provincia de Buenos Aires se encontraba en un lugar intermedio: sin que se hayan puesto muchas trabas, tampoco había mostrado un particular entusiasmo. Posteriormente, y hasta diciembre de 2015 (momento en el que se produjo un cambio de gestión), fueron realizándose en dicho distrito numerosas iniciativas tendientes a promover la implementación de la ESI. En efecto, durante el año 2015 se sancionó una ley provincial de ESI (14.744) que se enmarca explícitamente en la perspectiva de género y que tiene entre sus propósitos asegurar "el derecho al placer sexual", mención que no figura en la norma de alcance nacional. 
6. Para profundizar un análisis de la moral sexual pregonada por la Iglesia Católica, véase Esquivel (2013) y Romero (2017).
Por su parte, el director de una escuela perteneciente a la Universidad Católica de La Plata (UCALP), quien ya había admitido no conocer “a fondo" los contenidos de la ESI, planteaba que en materias "como Biología, o como Educación para la Salud, que enmarcan o se encuadran dentro de estas problemáticas”, es donde se daba cumplimiento a esta política. A su entender, la escuela no debía trascender esos límites, puesto que la formación en valores "se dirime en un ámbito muy personal, que puede llegar a ser la familia, o el individuo mismo" (Ariel, director de escuela de la UCALP). En estas reflexiones vemos cómo, pese a mostrarse favorable a la ESI y a plantear algunas críticas solapadas a la jerarquía eclesial — con alusiones a que "los tiempos cambiaron" y que "es hora de abrir las puertas a la realidad"-, su relato persistía en una concepción de la educación sexual como un derecho de los "padres" que recurría a un tradicional principio tutelar que no sólo es ajeno a esta ley, sino a casi toda la legislación vigente tanto en materia educativa como de niñez y adolescencia y que, en cambio, abreva en el ideario valorativo católico, ${ }^{6}$ reactualizado en los materiales producidos en contraposición a la ley 26.150 (Conferencia Episcopal Argentina [CEA], 2007).

Partiendo del mismo presupuesto - es decir, que la ESI impulsa una práctica pedagógica "preventiva"-, era radicalmente opuesto el camino escogido por Danilo, el director de un colegio perteneciente a una congregación de monjas, para quien esta política promovía "mucha información (...) pero creo que se queda mucho en algo más instrumental. [A su entender], la sexualidad tiene que estar un poquito más ampliada, el valor de la sexualidad en sí misma” (Danilo, director de escuela congregacional).

A medida que avanzaba en la indagación, fui notando la reiteración de este señalamiento en diferentes actores. Muchas/os de quienes criticaban la ESI confluían en el presupuesto de que se trataba de una iniciativa orientada a prevenir las consecuencias negativas de las relaciones coitales, pese a que esta política surgió precisamente para dar respuesta a la demanda de distintos sectores sociales (como el feminismo y los movimientos por la diversidad sexual) que pugnaban por trascender esa visión tradicional de la educación sexual, planteando un enfoque más amplio, orientado al reconocimiento y el ejercicio de los derechos sexuales y (no) reproductivos, la equidad de género y el respeto y la aceptación entre las personas con independencia de gustos, prácticas, deseos y aspectos.

¿Cómo comprender estas críticas a una política cuando movilizan nociones sobre ella que no se condicen con sus postulados? ¿Qué sentidos se anudan en estos malentendidos y qué valor heurístico pueden comportar para quien pretende comprender el marco de significaciones en el que se producen unas prácticas educativas específicas?

La ley 26.150 define a la educación sexual integral como aquella "que articula aspectos biológicos, psicológicos, sociales, afectivos y éticos” (Ley de Educación Sexual Integral, 26.150). Asimismo, sus lineamientos curriculares proponen una práctica pedagógica orientada a promover la capacidad de expresar libremente las diferentes "emociones" y "sentimientos" en relación con la sexualidad, de manera de trascender el reduccionismo en el abordaje de la sexualidad a su faz reproductiva/preventiva, así como a los presupuestos heteronormativos y patriarcales. ¿La exigencia de mayor amplitud en el enfoque por parte de Danilo expresaba simplemente un desconocimiento de estos postulados?

$\mathrm{Al}$ analizar la trama discursiva propuesta por este directivo, fue sencillo advertir que la amplitud exigida se orientaba en otra dirección. Para él, la escuela debía proveer a las/os estudiantes "un marco" de valores en cuyo seno él consideraba óptimo que se desenvolvieran las relaciones sexuales de las/os adolescentes, tal como comentó en una de las charlas que mantuvimos: 
Creo que a veces le faltaría un poquito más de profundizar en lo bueno que es tener relaciones sexuales en un marco, no de un amor idílico, de novela, pero sí en un marco de respeto, de compromiso, de responsabilidad (Danilo, director de escuela congregacional).

Como puede verse, se trataba de una visión centrada en el acto sexual, pero que pretendía trascender la formación en métodos anticonceptivos y enfatizar en la promoción de una moral sexual que operase como "marco" (también preventivo).

Resulta interesante advertir que los planteos de ambos directores - aunque divergentes en la orientación que a su entender debía tener la educación sexual en la escuela- partían del mismo supuesto respecto de la ESI (su carácter preventivo ligado a las relaciones coitales), a la vez que confluían en el ideario católico, aunque enfatizando distintos aspectos: dotar a la sexualidad de una espiritualidad orientada a reforzar los mandatos de género tradicionales (con eje en el modelo de la familia nuclear heterosexual) o bien evitar planteos que contradigan los valores familiares supuestos en vistas al respeto de la patria potestad. Lo notable es que, en ambos casos, las referencias al acervo católico eran más bien tenues, cuando no implícitas, situación que, más que como la puesta en práctica de lo que Juan Marco Vaggione ha denominado "secularismo estratégico", esto es, la movilización de un ideario religioso con argumentos no presentados como tales, sino adaptados a discursos "seculares" de mayor legitimidad en la vida moderna (Vaggione, 2009), a mi entender debería interpretarse como la simple naturalización de nociones de raigambre religiosa que se han sedimentado como sentido común (Williams, 2000).

Para avanzar en la comprensión de esa trama significativa, es preciso poner en relación esos testimonios con otros elementos relevados durante la investigación. Tanto en el discurso de quienes enfatizaban en la necesidad de promover hábitos de cuidado como en quienes consideraban propicio proveer a las/os estudiantes una moral que les permita enmarcar sus prácticas sexuales dentro de ciertos parámetros considerados deseables, saludables y legítimos, era posible advertir una serie de supuestos respecto de las/os jóvenes y sus hábitos, que en no pocos casos se anudaban con una concepción de pánico sexual, tal como veremos mejor a continuación.

\section{“Tratá de que no sea algo tipo animalesco". Adultocracia y pánico sexual}

“Lo que para uno era la edad de iniciación sexual no tiene nada que ver con lo que es hoy. El ambiente en el que se mueven, el alcohol en el que se mueven, hay chicos que tuvieron su primera relación sexual y ni se acuerdan. Es complicado el tema" (Alicia, docente de Formación religiosa de escuela congregacional).

El temor de docentes y directivos frente a la posible emergencia en el ámbito escolar de prácticas y discursos considerados habituales en la cotidianidad de las/os jóvenes al mismo tiempo que indeseables para el contexto educativo, podía observarse en el despliegue de toda una batería de operaciones tendientes a excluir del espacio institucional ese cúmulo de promiscuidades, excesos e irresponsabilidades que, de acuerdo con algunas/os adultas/os, constituían la experiencia cotidiana de las/os adolescentes.

Una de las formas más evidentes en que se expresaba este temor era en el énfasis puesto en el lenguaje utilizado, como si por esa vía pudieran colarse pasiones y nociones que no corresponderían al ámbito escolar. En ese sentido, una profesora me comentó: “yo lo que hago es que cada uno escriba una pregunta (...). Que lo hagan con respeto es lo primero que les digo, que no se sarpen" (Mariela, docente de Salud y adolescencia de escuela parroquial). Por su parte, otra docente me decía que el problema de esa 
7. Un recorrido genealógico más completo del concepto de "pánico moral" y su reconversión en el ámbito del feminismo como "pánico sexual" puede hallarse en Elizalde (2005). restricción era que, en muchos casos, las/os adolescentes "no conocen otro lenguaje, (...) entonces se quedan sin hacer la pregunta” (Gabriela, docente de Biología de escuela parroquial).

Sea que se habilite o no la utilización de un lenguaje sarpado, los recurrentes esfuerzos de docentes y directivos por constreñir la educación sexual dentro de "un marco de respeto", "serio", "con las palabras adecuadas, como tiene que ser", dan cuenta de cierto pavor por posibles desbordes que, se cree, el tema podría ocasionar en las/os adolescentes, al mismo tiempo que visibilizan la enorme gravitación de una ideología difusa pero potente que recubre las prácticas sexuales supuestas de las/os jóvenes bajo el manto de lo amenazante. De acuerdo con mi indagación, el efecto concreto en la cotidianidad escolar de este imaginario es la creación de escenarios educativos de baja intensidad, al horadar la confianza y el vínculo pedagógico y al escindir los contenidos curriculares de las experiencias, los deseos y las inquietudes de las/os estudiantes.

Se trata de una modalidad asentada, la mayoría de las veces, en una visión tradicional del proceso de enseñanza-aprendizaje, que concibe a quien aprende como un receptor de los saberes indiscutidos proporcionados por quien enseña, algo que excede lo estrictamente referido a la sexualidad, aunque tal vez emerja aquí con un énfasis particular al posibilitar a las/os docentes un mayor control de los intercambios respecto de temáticas que pueden llegar a incomodarlas/os a ellas/os mismas/os. En la excesiva prudencia que asumen las formas de abordar la educación sexual en las escuelas se observa, en simultáneo, una preocupación específica por las pasiones que esta pudiera despertar en las/os jóvenes, así como una ansiedad de las/os adultas/os por no saber qué ni cómo abordar lo que imaginan puede ser un universo nebuloso de promiscuidades, excesos y peligros. En diversas expresiones recogidas durante mi estadía en las escuelas observé que muchas veces un obstáculo importante para plantear diálogos francos sobre la sexualidad de las/os adolescentes consistía en que estas/os eran visualizadas/os por las/os adultas/os a partir del prisma del pánico moral o, para decirlo con más precisión, del pánico sexual. ${ }^{7}$

El concepto de pánico moral - acuñado por diversos estudios sociológicos británicos a principios de los años setenta - refiere a una ideología difusa que tiende a expresarse vagamente en defensa del bien común, adaptándose de manera estratégica a diversas situaciones y prácticas emergentes que son definidas como una amenaza para el orden público, por lo que merecen ser controladas, reprimidas y/o sancionadas. Como es sencillo advertir, esta noción excede ampliamente el universo de las prácticas sexuales de las/os adolescentes. Pibes chorros, piqueteros, barrabravas, manteros son algunas de las figuras contemporáneas que recaen bajo su órbita al ser declaradas como principales enemigas de un supuesto bien común. Inadaptados, violentos, antisociales son algunas de las maneras de referirse a los sujetos que encarnan esa amenaza pública.

Ahora bien, esta aversión hacia las prácticas disidentes que atentan contra el orden social adquieren una formación discursiva específica en lo concerniente a las sexualidades y los géneros. La aprensión hacia la disidencia sexual suele expresarse de otros modos, escogiendo muchas veces el solapamiento y la invisibilización, antes que su puesta en escena y su (híper)visibilidad pública. De ahí que optemos por hablar de pánico sexual para referirnos a este dispositivo de autoridad. Aún a través de las alusiones, los silencios y los pretendidos ocultamientos, esta ideología se vincula con los sujetos y prácticas que son su objeto de regulación a partir de haberlas definido previamente como "problema" (Elizalde, 2005).

En las entrevistas mantenidas en las escuelas podemos advertir la pregnancia de esta perspectiva, presente en las palabras de una docente cuando, al referirse a los saberes previos de sus estudiantes, aseguraba que toda "la información que tienen es 
pornografía" (Patricia, docente de Biología de escuela congregacional). Por su parte, la profesora que citamos al comienzo de este apartado reforzaba esa visión al plantear que "hay chicos que tuvieron su primera relación sexual y ni se acuerdan" (Alicia, docente de formación religiosa de escuela congregacional). Una mañana que conversábamos con el director de una de las escuelas respecto del mejor modo de abordar la educación sexual, me señaló que lo primero que le diría a un estudiante si lo viene a consultar sería: "si te toca un fin de semana, tratá de que no sea algo tipo animalesco, que sea dentro de todo con un compromiso, por lo menos que sepas lo que estás haciendo" (Danilo, director de escuela congregacional). En el mismo sentido puede interpretarse un comentario que me hizo una profesora de otro colegio, para quien resultaba prioritario "que los chicos aprendan a respetarse a sí mismos, a quererse, el tema de no a la promiscuidad, hoy con uno, mañana con el otro" (Lorena, docente de Biología de escuela de la UCALP), que a su entender era lo que sucedía cotidianamente.

Sea por ignorancia, por la afectación de ciertos consumos (drogas, alcohol, pornografía), por "promiscuidad" o por falta de autoestima o de respeto de sí, hay en estos testimonios fragmentos discursivos que confluyen en una caracterización del universo de las prácticas sexuales juveniles como problemático.

Frente a ese universo oscuro y amenazante, las prácticas pedagógicas tendían a orientarse en otra dirección, cubriendo con un manto de silencio la experiencia supuesta de las/os jóvenes y planteando el abordaje de la sexualidad en términos estrictamente técnicos, racionales y circunscriptos a unos momentos particulares de la vida escolar.

La educación sexual escolar aparecía así como un momento específico, delimitado, que escindía los conocimientos de la experiencia. Esto podía advertirse con claridad en las evaluaciones, instancia en la que docentes e instituciones jerarquizan los saberes considerados valiosos. Las prácticas sexuales de las/os jóvenes, sus valoraciones respecto de diversos tópicos como aborto, homosexualidad, relaciones sexuales escindidas del matrimonio y de una voluntad de reproducción que de alguna u otra forma emergían en las aulas eran temas que quedaban excluidos de los exámenes. Por el contrario, estas/ os docentes exigían de cada estudiante, como condición de aprobación de los cursos, la incorporación de un mínimo de conocimientos referidos al cuerpo humano, a la función que cumplen determinados órganos y al contenido de algunas leyes referidas a salud sexual y reproductiva. Los debates y discusiones que eventualmente se producían en torno a otros ejes eran dejados de lado, marginados a situaciones aisladas y subordinados frente a aquello que aparecía como prioritario y digno de ser estudiado y aprehendido. Por lo demás, en los exámenes relevados en los que se evaluaba la educación sexual deliberadamente impartida, las/os jóvenes eran convocadas/os a repetir las definiciones proporcionadas por las/os profesoras/es, aunque al conversar con ellas/ os aseguraran que en sus clases surgían "interesantes debates".

Estas dinámicas institucionales vuelven evidente el pavor que muchas/os adultas/os experimentan ante las prácticas sexuales supuestas de las/os jóvenes, así como ante los riesgos que se imaginan puede suscitar convocar en la escuela sus deseos y experiencias, entre los que cabría incluir la posibilidad de no estar a la altura de las circunstancias o bien de verse interpelados respecto de su propia sexualidad, algo que puede desestabilizar el lugar de autoridad pedagógica construido. Una cosa es la adscripción retórica a ciertos posicionamientos políticamente correctos y otra muy distinta es sostener esas mismas posiciones cuando se pone en juego algo del orden de la experiencia y los sentidos hondamente calados en la propia subjetividad de las/os profesoras/es.

Un ejemplo de ello fue lo que me sucedió durante una charla que mantuve con una docente de Salud y Adolescencia. Tanto en entrevistas previas como en una de sus clases que presencié fue muy clara en que, a su entender, la homosexualidad "es una 
elección", algo que ella veía que a sus estudiantes les costaba asumir, pues consideraban que se trataba de "una cuestión genética". Según me dijo: esa es "la idea que todos traen". Sin embargo, ese día, conversando en el patio de la escuela respecto de cómo la ley de matrimonio igualitario había impactado en las aulas, tuvo un cambio de actitud, y manifestó sentimientos hasta entonces no invocados.

Al comienzo, el tono de la conversación fue en la misma línea de corrección política que ya habíamos seguido en otros encuentros:

(...) como les decía con la ley de matrimonio igualitario y la ley de adopción gay, no necesariamente de una pareja gay van a salir hijos homosexuales. Me parece que es una elección de vida, como uno elige tener relaciones heterosexuales, otros eligen tener relaciones homosexuales (Griselda, docente de Salud y adolescencia de escuela congregacional).

Posteriormente, como si la sola invocación de la imagen de una pareja del mismo sexo hubiera generado una sensación irrefrenable, agregó:

Yo lo respeto, hasta un punto. Es medio molesto que dos mujeres o dos hombres se estén besando delante de uno. (...) Yo lo respeto mientras que sea dentro del ámbito personal, de su vida, pero respetando también la cultura en la que viven, la cultura a la que pertenecen, los valores (Griselda, docente de Salud y adolescencia de escuela congregacional).

Después, con evidente disgusto y con gran incomodidad, acaso con algo de vergüenza de sí, señaló: "respeto las decisiones, no es una enfermedad, es una decisión, como cualquier otra opción sexual, pero sí te puedo decir que me causa pudor cuando dos personas del mismo sexo se están besando" (Griselda, docente de Salud y adolescencia de escuela congregacional).

De ahí que sugiera que en la apelación recurrente por parte de las/os docentes a la "falta de capacitación" o bien a que "vengan especialistas" para dar educación sexual, es preciso leer asimismo cierto temor respecto de lo que podría despertar en ellas/os el abordaje integral y profundo del tema. Allí radica uno de los motivos por los que algunas/os opten, cuando no tienen más alternativa que tratar ciertos asuntos vinculados a la sexualidad, por circunscribirlos dentro de un discurso biomédico que parecería ofrecer ciertas garantías de eficacia a la hora de enfriar y contener las emociones, al convertirlos en contenido curricular escindido de las experiencias cotidianas y alejado todavía más de ellas a partir del uso de un lenguaje técnico que se distancia ostensiblemente del habla habitual.

Por su parte, las/os docentes que despliegan un enfoque más horizontal e interesado por las opiniones y las prácticas de las/os jóvenes tienen una experiencia educativa que contrasta drásticamente con ese imaginario. Sin embargo, la ausencia de diálogos francos entre los diferentes actores institucionales - en parte debido al temor de que trasciendan los distintos abordajes de la sexualidad que coexisten en cada institución educativa religiosa - no hace más que reforzar los supuestos vinculados al pánico sexual, lo cual ahonda las distancias y los malentendidos.

\section{Reflexiones finales}

Desde el año 2006, la Argentina cuenta con una ley (26.150) de Educación Sexual Integral (ESI) que tensiona el sistema sexo-genérico patriarcal, machista, procreacionista y heteronormativo vigente, al postular una definición constructivista de la 
sexualidad, promover la equidad de género y la aceptación de las diversas formas de vivir y experimentar la sexualidad y el género, escindir la sexualidad de la reproducción y habilitar la dimensión del placer. En rigor, muchos de estos aspectos no estaban planteados en la ley 26.150, sino que fueron gestándose lentamente a partir del desarrollo del Programa Nacional de ESI creado por la misma norma, que fue incorporando en su despliegue nuevas demandas y contenidos no tenidos en cuenta inicialmente o que había sido preciso postergar con el fin de lograr los consensos necesarios para su aprobación (el texto finalmente aprobado tuvo sólo un voto en contra en cada una de las cámaras legislativas) ${ }^{8}$

Si bien la sanción de esta ley estuvo rodeada por fuertes debates públicos, especialmente por la enfática oposición planteada por sectores conservadores de la Iglesia católica, lo cierto es que se inserta en un entramado normativo gestado en las últimas décadas en torno a sexualidad, familia y reproducción (Brown, 2008; Pecheny y Petracci, 2010), así como en un contexto más específico en el que el Estado recuperó parte de su potencia interpeladora en varios aspectos, entre ellos, el educativo.

Una lectura apresurada de ese entramado normativo podría llevarnos a postular erróneamente la idea de un avance progresivo e inexorable en materia de equidad de género y de garantías para el desarrollo pleno de una autonomía para decidir sobre el cuerpo y la vida propios. Sin embargo, basta señalar simplemente la renuencia de la mayor parte de las/os legisladoras/es para tratar un proyecto de legalización del aborto, así como algunos retrocesos en el nuevo Código Civil y Comercial sancionado luego de la asunción de Jorge Bergoglio al frente del Vaticano para ilustrar las contradicciones y complejidades que nutren estos procesos.

Por otra parte, y es este el aspecto que resulta de mayor interés a los fines de este trabajo, existe otro tipo de obstáculos que dificultan la aplicación plena e integral de algunas de estas leyes, entre los que se cuentan los idearios valorativos, así como las trayectorias formativas y profesionales de quienes deben instrumentarlas. En el caso de la ESI, la cuestión es especialmente relevante por cuanto para muchas/os docentes, el abordaje de la sexualidad invoca sentimientos de vergüenza, pudor, incertidumbre y, en algunos casos, asco y repugnancia. En ocasiones, es la inseguridad por no saber si van a poder mantener a raya estos sentimientos hondamente calados lo que hace que decidan eludir el tema o bien que, en aquellas asignaturas que prescriben obligatoriamente su abordaje, este quede restringido a unos contenidos mínimos vinculados a su faz biomecánica y/o a la enumeración de métodos de prevención de enfermedades y de embarazos indeseados, por lo general con una abundancia de lenguaje técnico que desconecta los procesos educativos de la cotidianeidad de los sujetos implicados en ellos.

Prácticamente toda la literatura producida en los últimos años coincide en caracterizar este enfoque biomédico como la perspectiva que hegemoniza las prácticas de educación sexual en el ámbito escolar. Sin embargo, no siempre se ha reflexionado suficientemente acerca de las razones de su carácter dominante en dichos contextos, por lo general asumiendo que se trata sencillamente de una visión que predomina en las valoraciones de los sujetos, como si sus formas de proceder no estuvieran condicionadas por el marco y la trama institucional en que se hallan insertos. Siguiendo a Restrepo, considero que el contexto institucional no es meramente el telón de fondo sobre el que suceden las cosas, sino la condición de posibilidad para que esas cosas - y no otras - ocurran (Restrepo, 2011). De ahí que en este trabajo haya optado por dar un paso más en ese sentido. Desde una perspectiva radicalmente contextualista que, siguiendo a Stuart Hall, asume la premisa que señala que "importa lo que es en situaciones particulares" (Hall, citado en Grossberg, 2009: 18), en este caso me interesó preguntarme por los sentidos puestos en juego en las tres escuelas católicas indagadas,
8. Correspondientes al diputado Roberto Lix Klett y la senadora Liliana Negre de Alonso. 
para destacar el valor específico de los procesos estudiados y evitar la generalización a partir de sus particularidades.

Conviene aclarar que la noción de contexto institucional aquí empleada (en tanto ambiente específico y cambiante a la vez constituido y constitutivo de las prácticas escolares analizadas) se distingue del concepto de cultura institucional, que puede tender a reificar los procesos en curso cuya dinámica de transformación es preciso estudiar así como a subestimar la capacidad de agencia de los sujetos (Ortner, 2005).

En suma, lo que pretendo señalar es que no considero que del carácter dominante del enfoque biomédico en las experiencias de educación sexual estudiadas deba derivarse ni su posición hegemónica en el orden social más amplio ni en los sentidos sociales vinculados a géneros y sexualidades de los sujetos que habitaban estas escuelas al momento de la indagación. Consecuentemente, emerge como interrogante la cuestión de su predominio en las prácticas analizadas.

De acuerdo con el recorrido trazado en este artículo, mi hipótesis es que la perspectiva biomédica opera como una formación discursiva legítima y relativamente eficaz (en tanto gobierno del aula) a la hora de afrontar ciertos tópicos que tanto directivos como docentes presumen que podría generar desbordes en las/os jóvenes, así como invocar en las/os propias/os adultas/os sentimientos de vergüenza, pudor e incluso repugnancia o asco. Sentimientos "innobles" (Figari, 2009) que la constricción de la sexualidad a su faz reproductiva y biomecánica, abordada a partir de un lenguaje técnico completamente alejado del habla y la experiencia cotidianos, parecería ofrecer credenciales de poder contener.

Si esta hipótesis es cierta, una manera crucial de desestabilizar esta forma poderosa de concebir la educación sexual consistiría en apostar a formaciones pedagógicas que se atrevan al mismo tiempo a descentrar el aprendizaje de la razón, así como a la sexualidad de la genitalidad y el coito. Se trata de poner en el centro de la escena a los cuerpos - sexuados, sensibles, deseantes y pensantes- que protagonizan los procesos educativos. Cuerpos de jóvenes y adultas/os de cuya interacción surgen los aprendizajes y que en los colegios estudiados demasiado a menudo se los pretendía reconocer como meros portadores de intelecto y, a lo sumo, de funciones biomecánicas.

Al poner al cuerpo en el corazón del proyecto educativo, resultará inevitable incorporar a las prácticas pedagógicas la dimensión del placer, de los sentimientos y de las emociones (Morgade, 2011), ejes cruciales aunque a veces negados en las diferentes experiencias relevadas. A mi entender, ahí radica una vía fructífera para erigir las escuelas en escenarios formativos y de socialización realmente significativos.

Por otro lado, es preciso señalar que, si bien la mera existencia de la ley no garantiza el abordaje de una educación sexual igualitaria, varias/os docentes se refirieron a ella como un respaldo importante para correrse con mayor tranquilidad de la moral sexual católica. Ahora bien, al mismo tiempo, resulta interesante señalar que las prácticas que esta norma habilita no necesariamente se orientan en su misma dirección, a menos que entendamos que la perspectiva biomédica es un paso intermedio entre un enfoque de género y la educación para el amor pregonada por la Conferencia Episcopal Argentina.

Aun para quienes consideran que la perspectiva biomédica constituye un avance, debería mantenerse cierta prudencia antes de asumir que se trata de un acercamiento a la postura que impulsa la ESI. Antes bien, las prácticas analizadas permiten advertir que, al menos en las escuelas confesionales católicas, esta política pública ofrece un importante respaldo para un desplazamiento legítimo de algunos preceptos normativos religiosos, sin que ello implique el cuestionamiento de muchos de los supuestos 
sobre los que descansa el ordenamiento sexo-genérico vigente. Por muchos logros que se hayan conquistado en el plano normativo en los últimos años, ello no implica una progresividad inevitable hacia una sociedad más justa. No se trata de una cuestión de tiempo. Si una perspectiva de género y de derechos se impone como hegemónica, será por el resultado (contingente) de una batalla político-cultural y no por la garantía de un tránsito seguro hacia un destino inexorable.

Por lo demás, observamos que la apariencia natural, supuestamente no ideológica del enfoque biomédico, la vuelve una barrera difícil de advertir, como si sus postulados constituyeran el piso incuestionable a partir del cual es posible luego incorporar diferentes énfasis y valoraciones. Al asumir el cuerpo como mandato biológico - y no como construcción social-, al no desmontar mitos y estereotipos acerca de las sexualidades e identidades masculinas y femeninas, este paradigma refuerza el ordenamiento hegemónico que es patriarcal, heterosexista y procreacionista, es decir, profundamente violento. Aun cuando aquí preferimos distinguir gradaciones en el ejercicio de las violencias, esto es, no creemos que una práctica pedagógica androcéntrica tenga la misma gravedad que una situación de abuso sexual, lo cierto es que ambas acciones forman parte de una misma "formación discursiva" (Foucault, 2002), en la medida en que una sociedad golpea, viola y mata en forma sistemática a aquellos sujetos a los que previamente inferiorizó, discriminó, fragilizó (Fernández, 2009). Sin señalar que se trate del ámbito donde se elaboren estas clasificaciones y jerarquías, es claro que la escuela puede cumplir un rol central en la interrupción de esos circuitos de violencia.

En este sentido, me interesó relevar el complejo entramado de referencias múltiples, malentendidos y confusiones respecto de los contenidos curriculares impulsados por la ESI. Lo que advertí es que sus resonancias institucionales son bastante difusas y opacas y requieren de una analítica situada capaz de anclar las prácticas y los testimonios relevados en tramas simbólicas más abarcativas en las que adquieren sentido. En algunos casos, noté que esta política no llegó a establecerse siquiera como parámetro preciso a partir del cual posicionarse, y ello vale tanto para quienes disienten con sus postulados supuestos como para quienes los celebran. Algunas/os de nuestras/os informantes confundían la ESI con los contenidos de algún manual elaborado por una editorial privada, otras/os decían "conocerla" a partir de las críticas realizadas por la jerarquía eclesial, otras/os, por su repercusión mediática. En este marco, resultó un desafío epistemológico crucial la pregunta acerca de cómo interpretar estos datos recogidos en nuestra experiencia etnográfica. ¿Vale la pena hablar de resistencias y de desvíos allí donde la norma (legal) no parece llegar a ser reconocida? Desde mi punto de vista, lo relevante consiste no sólo en registrar los desvíos, sino también, y por sobre todas las cosas, en poner las prácticas en contexto y advertir su orientación ideológica. De ahí que haya optado por hacer una lectura teórico-política de las experiencias de educación sexual analizadas y no meramente una constatación de su mayor o menor adecuación respecto de los contenidos curriculares oficiales o del ideario valorativo católico.

Asimismo, está claro que no alcanza con el despliegue de políticas públicas transformadoras, si tales iniciativas no encuentran una articulación con otras prácticas y discursos orientados en la misma dirección. Como puede advertirse en este trabajo, algunas operaciones de fronterización han sido tan exitosas que sus sentidos resultantes se hallan alojados en los sentimientos más hondos de las subjetividades. El asco, el pudor, la vergüenza emergen como reacciones casi espontáneas o instintivas que ponen frenos muy precisos a la incorporación de nuevos saberes y formas de hacer, y ello se expresa de manera particular en el terreno de los géneros y las sexualidades (Nussbaum, 2006; Figari, 2009). En algunos casos, habrá que aceptar que el proceso será largo y que implicará romper formaciones culturales de mucho arraigo. Para ello resultará fundamental contar con capacitaciones docentes que promuevan experiencias educativas desde un enfoque de interculturalidad, que rompan con la falsa homogeneidad que la escuela 
(y en general el Estado) ha pretendido administrar. No se trata de tolerar la diferencia, sino de integrarla, de aceptarla, partiendo del supuesto de que toda experiencia humana es, desde que tenemos registro, intercultural.

El obstáculo no es meramente retórico, como algunos cambios curriculares parecen sugerir, sino que es preciso conmover los sentidos hondamente calados en los sujetos que intervienen en los procesos educativos. A partir de las experiencias pedagógicas analizadas en este trabajo, puede señalarse que este reto asume un doble desafío: por un lado, el de ubicar los cuerpos sexuados de profesoras/es, directivos y estudiantes en el centro de la escena, y ello tanto en lo concerniente a la dinámica cotidiana en las instituciones escolares, como a los procesos de formación de las/os propias/os docentes. Más que incorporar nuevos términos o conocer nuevas legislaciones ancladas en un paradigma de derechos humanos, el reto consiste en conmover formas de sentir y de emocionarse, y ello no es alcanzable solamente a través de la razón. Es preciso, por tanto, burlar las trampas de lo políticamente correcto e interpelar aquello que repugna, que asquea, en tanto allí se aloja una frontera cultural frente a la cual se establece un nosotros. Las experiencias cotidianas, los deseos, las ansiedades, las emociones y los placeres de los sujetos que interactúan en las escuelas deben constituir el corazón de los proyectos educativos, a fin de establecer experiencias altamente significativas. Por otro lado, la indagación realizada nos arroja la profunda certeza de que, para que ello sea posible, resulta fundamental un mayor compromiso por parte del Estado, tanto en lo relativo a la formación docente, como en cuanto al control y acompañamiento de las prácticas cotidianas de las escuelas, que en el caso de las tres instituciones aquí analizadas, operaban con tales grados de autonomía respecto de los contenidos prescriptos, que ponían en tensión la mera posibilidad de que sus estudiantes ejerzan algunos de los derechos garantizados por ley, como es el caso de la educación sexual integral. 


\section{Q Bibliografía}

"BROWN, Josefina. 2008. Mujeres y ciudadanía en Argentina. Debates teóricos y políticos sobre derechos (no)reproductivos y sexuales (1990-2006). Tesis de Doctrorado, Facultad de Ciencias Sociales, Universidad de Buenos Aires.

" ELIZALDE, Silvia. 2005. La otra mitad. Retóricas de la "peligrosidad" juvenil. Un análisis desde el género. Tesis de Doctorado, Facultad de Filosofía y Letras, Universidad de Buenos Aires.

» ESQUIVEL, Juan Cruz. 2013. Cuestión de educación (sexual). Pujas y negociaciones políticoreligiosas en la Argentina democrática. Buenos Aires: Clacso.

" FERNÁNDEZ, Ana María. 2009. Las lógicas sexuales: amor, política y violencia. Buenos Aires: Nueva Visión.

" FIGARI, Carlos. 2009. “Las emociones de lo abyecto: repugnancia e indignación”. En: A. Scribano y C. Figari (Comps.). Cuerpo(s), subjetividad(es) y conflicto(s). Hacia una sociología de los cuerpos y las emociones desde América Latina. Buenos Aires: Clacso/Ciccus. pp. 131-140.

"FOUCAULT, Michel. 2002. La arqueología del saber. Buenos Aires: Siglo XXI.

" FOUCAULT, Michel 2011. Historia de la sexualidad. Tomo 1, La voluntad de saber. Buenos Aires: Siglo XXI.

» GROSSBERG, Lawrence. 2009. “El corazón de los estudios culturales: Contextualidad, construccionismo y complejidad". Tabula Rasa, 10: 13-48.

» MORGADE, Graciela (Coord.). 2011. Toda educación es sexual. Hacia una educación sexuada justa. Buenos Aires: La Crujía.

"NUSSBAUM, Martha. 2006. El ocultamiento de lo humano. Repugnancia, vergüenza y ley. Buenos Aires: Katz.

" ORTNER, Sherry. 2005. "Geertz, subjetividad y conciencia posmoderna”. Etnografías Contemporáneas, 1(1): 25-54.

» PECHENY, Mario y PETRACCI, Mónica. 2010. "Panorama de derechos sexuales y reproductivos, Argentina 2009". Argumentos, 11: 38-62.

" RESTREPO, Eduardo. 2011. "Estudios culturales y educación: Posibilidades, urgencias y limitaciones". Cuarto Seminário Brasileiro de Estudos Culturais e Educação y 10 Seminário Internacional de Estudos Culturais e Educação. Porto Alegre: ULBRA-Canoas/RS.

"ROMERO, Guillermo. 2017. "Chicos, ahora vamos a hablar de sexualidad". Prácticas, discursos, regulaciones y tensiones en la implementación de la educación sexual en escuelas confesionales católicas de la ciudad de La Plata. Tesis de Maestria, Universidad Nacional de San Martín.

" TOMASINI, Marina. 2011. "Relaciones peligrosas. Prácticas y experiencias en torno a la sexualidad de las jóvenes en el inicio de la escuela media". Astrolabio, 6: 107-126.

"VAGGIONE, Juan Marco. 2009. "La sexualidad en un mundo post secular. El activismo religioso y los derechos sexuales y reproductivos". En: M. Gerlero (ed.). Derecho a la sexualidad, Buenos Aires: Grimberg. pp. 141-159.

» WILLIAMS, Raymond. 2000. Marxismo y Literatura. Barcelona: Península. 


\section{Otras fuentes consultadas}

»CEA. 2007. Educación para el amor. Plan general y cartillas. Buenos Aires: Conferencia Episcopal Argentina.

» DISEÑO CURRICULAR PARA LA EDUCACIÓN SECUNDARIA 1 AÑO, capítulo “CIENCIAS NATURALES". Año 2006. Dirección General de Cultura y Educación de la Provincia de Buenos Aires (coordinado por Ariel Zysman y Marina Paulozzo).

" DISEÑO CURRICULAR PARA LA EDUCACIÓN SECUNDARIA: “Construcción de Ciudadanía". $1^{\circ}$ a $3^{\circ}$ año. Año 2007. Dirección General de Cultura y Educación de la Provincia de Buenos Aires (coordinado por Ariel Zysman y Marina Paulozzo).

" DISEÑO CURRICULAR PARA LA EDUCACIÓN SECUNDARIA: "Salud y Adolescencia”. Año 2010. Dirección General de Cultura y Educación de la Provincia de Buenos Aires (coordinado por Claudia Bracchi).

» EDUCACIÓN SEXUAL INTEGRAL PARA LA EDUCACIÓN SECUNDARIA II. 2012. Serie "Cuadernos de ESI". Programa Nacional de Educación Sexual Integral, Ministerio de Educación de la Nación.

» EDUCACIÓN SEXUAL INTEGRAL PARA LA EDUCACIÓN SECUNDARIA. 2010. Serie "Cuadernos de ESI". Programa Nacional de Educación Sexual Integral, Ministerio de Educación de la Nación.

" LEY NACIONAL 26.150 DE EDUCACIÓN SEXUAL INTEGRAL.

» LEY PROVINCIAL 14.744 DE EDUCACIÓN SEXUAL INTEGRAL. Provincia de Buenos Aires.

» LINEAMIENTOS CURRICULARES PARA LA EDUCACIÓN SEXUAL INTEGRAL. 2008. Programa Nacional de Educación Sexual Integral, Ministerio de Educación de la Nación, Consejo Federal de educación. 